\title{
EL CUERPO DE LA CRISIS. LA CIUDAD Y SUS SINTOMATOLOGÍAS EN EL PAISAJE URBANO
}

\author{
Ana Carrasco-Conde \\ Universidad Complutense de Madrid \\ Universidad Politécnica de Madrid \\ Campus of International Excellence
}

http://dx.doi.org/10.5209/rev_NOMA.2013.v40.n4.48331

\begin{abstract}
Resumen.- El artículo parte de la consideración organicista de la ciudad como cuerpo orgánico, cuya génesis se remonta a Aristóteles y es retomada por Francesco Patrizzi en La città felice (1553), para establecer un análisis de la sintomatología de la crisis entendida como enfermedad (Cfr. R. Koselleck) en el tejido urbano.
\end{abstract}

Palabras clave.- ciudad, crisis, cuerpo, Aristóteles, Francesco Patrizzi, R. Koselleck

Abstract.- The article starts from the organic consideration of the city as body, which genesis goes back to Aristotle and is taken again on the Renaissance epoch by Francesco Patrizzi in La città felice (1553), to establish an analysis of the symptomatology of the crisis understood as disease (Cfr. R. Koselleck) in the urban fabric.

Keywords.- city, crisis, body, Aristotle, Francesco Patrizzi, R. Koselleck

Empecemos por lo manido o por aquello que, de tanto ser mentado en los últimos tiempos, del logos ha pasado casi al uso mítico ${ }^{1}$ : desde Crítica y crisis. Un estudio sobre la patogénesis del mundo burgués, la disertación de Reinhart Koselleck (1954), sabemos que el concepto crisis (gr. krisis) es un término originalmente médico (no político, no social, no económico), vinculado tanto a clínica (gr. klinikos, de klini, cama o lecho, también "punto crítico de la vida humana" ${ }^{2}$, por extensión, el médico, el que va "de cama en cama") como a crítica (gr. krino, separar el grano de la paja y de ahí juzgar y enjuiciamiento). Crisis quiere decir en este contexto, en el ámbito biológico, el momento clave en el que, en el decurso de una enfermedad, lo que no mata hace más fuerte, es decir el momento, el punto, la cúspide de una evolución, en la que el enfermo o vive o muere. Está, por tanto, referido a una patología, y no a un correcto funcionamiento del organismo, no tanto en el sentido del ataque externo de un ente alieno, sino al de un desequilibrio interno en el organismo mismo. Así, por cierto, es empleado por Galeno, que hace (buen) uso del

\footnotetext{
${ }^{1}$ Trabajo espléndido sobre ésta y otras mitologías de la crisis, vinculadas al ámbito de lo económico, es el de Rocío Orsi y Andrés González: "La construcción mitológica de la crisis" (2013). Disponible: http://www.aecpa.es/uploads/files/modules/congress/11/papers/973.pdf (Consultado el 9 de dicuembre de 2013)

${ }^{2}$ Cfr. (1970) CHANTRAINE, Pierre: Dictionnaire étymologie de la langue grecque. Histoire des mots, tomo II E-K, Paris, Klincksieck, p. 543.
} 
Corpus Hippocratium en el que se encuentra toda una teoría médica en torno a la crisis y al equilibrio entre los cuatro humores ${ }^{3}$. Pero el concepto crisis no se agota en el uso médico, como recuerda el propio Koselleck, aunque siga nutriéndose de su sentido, y pasa a ser utilizado por Tucídides para señalar este punto clave, pero referido a otro contexto: el de las guerras, por las viven o mueren pueblos enteros. Designa así en su Historia de la guerra del Peloponeso las batallas decisivas que conducirían al fin de la guerra. Y así, con esta nueva polisemia, reaparece de nuevo en la Política de Aristóteles, quien usó esta expresión para designar no tanto este "punto de equilibrio inestable" sino las grandes decisiones tomadas en la polis y que determinaban la ordenación de la comunidad cívica, la decisión, por tanto, que conduce a su caída o a su salvación: la elección de cargos, resoluciones de gobierno, toma de decisiones sobre la guerra y la paz, la aplicación de penas de muerte o la condonación de una condena ${ }^{4}$. Un punto pues de breve indecisión, por recordar anacrónicamente el Scheidenpunkt schellinguiano, y por el que Schelling vinculará, por cierto, krisis y enfermedad en el seno de la divinidad ${ }^{5}$. No deja de ser interesante que sea precisamente Aristóteles y precisamente en la Política, el que aplique un término propio del ámbito médico al ámbito de la ciudad. Y no lo es porque en esta misma obra el que fuera tutor de Alejandro Magno, el gran fundador de las ciudades, concibe la ciudad biológicamente como un cuerpo orgánico y vivo. De igual manera que antes del órgano está el cuerpo, antes del hombre está la polis; y la polis, como tal, es lo más característico, lo más natural, del hombre.

La concepción aristotélica de la ciudad como algo natural, como un ser vivo y orgánico se inscribe dentro de la crítica a los sofistas para los cuales todo lo que tenga que ver con las relaciones entre los hombres es producto de la convención y no algo natural, piénsese en las afirmaciones de Altifonte o Licofrón acerca de la igualdad de todos los hombres, sin importar su raza, su clase social o su condición de esclavos $^{6}$. Construimos la ciudad, como construimos leyes: podemos intervenir en ellas a nuestro antojo ya que éstas son mero consenso; pero no así para Aristóteles: la ciudad no es un producto, sino un proceso, lo que proporciona "vida" a los individuos y las leyes afectan directamente el funcionamiento de un sistema orgánico. Recordemos el pasaje del libro I de la Política según el cual "es evidente que la ciudad es una de las cosas naturales y que el hombre es por naturaleza un animal social [...] Por naturaleza, pues, la ciudad es anterior a la casa y a cada uno de nosotros, porque el todo es necesariamente anterior a la parte. En efecto, destruido el todo, ya no habrá pie ni mano, a no ser con nombre equívoco como se puede decir una mano de piedra: pues tal será una mano muerta"7 y también "la

\footnotetext{
3 "El cuerpo humano contiene sangre, flema, bilis amarilla y bilis negra; es ello lo que constituye su naturaleza y lo que crea en él la enfermedad y la salud". En (ed. 1973) HIPÓCRATES: "Sobre la naturaleza del humano", Ouvres complètes d'Hippocrate, ed. Littre, VI, 38-40.

${ }^{4}$ (2007) KOSELLECK, Reinhart: "Apéndice. Crisis" en Crítica y crisis. Un estudio sobre la patogénesis del mundo burgués, Madrid, Trotta, pp. 241-242.

${ }^{5}$ (2014) CARRASCO-CONDE, Ana: "Ens alienum. El mal visto desde la Naturphilosophie en F.W.J. Schelling". En: Silvia del Lujan Di Sanza y Diana María López: El vuelo del búho. Estudios sobre filosofía del idealismo, Buenos Aires, Editorial Prometeo Libros.

${ }^{6}$ (2012) Cfr. GUTHRIE, W.K.C.: Historia de la filosofía griega, II, Gredos, Madrid, p. 165 y ss.

${ }^{7}$ Política, 1253a; también Ética a Nicómaco, IX 9, 1169 b16 y ss. Sobre la polis y la política en Aristóteles remito al autor a los clásicos de Rodriguez Adrados: La democracia ateniense, Madrid, Alianza, 1985; el de Salvador Mas: Ethos y polis. Una historia de la filosofía práctica en
} 
ciudad es por naturaleza y es anterior al individuo"8. La crisis, por tanto, es un momento crucial, de vida o muerte, en el que se decide la suerte de la polis, como, en el ámbito médico se decide la suerte del enfermo, pero no de un modo metafórico o conceptual, sino de un modo bien real. La ciudad como cuerpo es susceptible de sufrir una crisis $y$, por tanto, de padecer una enfermedad que conduzca hasta ella, pero si hay enfermedad ésta es reconocida inicialmente por sus síntomas. No en vano, la clínica médica procede al diagnóstico por reconocimiento de una sintomatología. Lo que trataré de exponer en lo que sigue es la síntomatología de la crisis en una ciudad entendida como cuerpo orgánico y vivo, con sus marcas y señales, con sus inflamaciones y sus supuraciones, una idea que puede ser rastreada tanto en Francesco Patrizzi en su Ciudad feliz (1553) como en Ficino ${ }^{9}$. Para ello vertebraré mi intervención en tres partes: I) La primera consagrada a la idea de la ciudad como cuerpo; II) la segunda profundizará en la sintomatología de la crisis en la ciudad; III) y la tercera que tratará de diagnosticar la enfermedad y dar cuenta koselleckianamente del horizonte de expectativas.

\section{LA CIUDAD COMO CUERPO}

Empezamos bien. Donde dije digo, digo Diego. Koselleck, en el mismo texto ya citado, afirma que "aunque la metafórica del cuerpo y del organismo se ha aplicado desde la Antigüedad a la comunidad, el concepto médico de crisis no parece haber sido puesto en relación con los cuerpos políticos, o con sus órganos, hasta el siglo XVII"10. Esta afirmación nos hace pensar que, la referencia del propio Koselleck al uso que hace Aristóteles del concepto de "crisis", no se aplicaría a la forma de gobierno, sino a la ciudad misma. Y, sin embargo, el propio Koselleck menciona, poco antes, el uso del concepto en el ámbito clave de decisiones políticas ${ }^{11}$. Ahora bien, polis quiere decir en Aristóteles, cuerpo: el cuerpo de la polis entendido como un todo cuya salud depende del exacto equilibrio entre sus partes ${ }^{12}$. Aunque dejamos para otra ocasión la discusión más explícita sobre el polémico y clasista equilibrio -que, por naturaleza hace de algunos señores y de otros esclavos-, al hablar de la relación entre el dominante y el dominado, Aristóteles introduce una interesante analogía: del mismo modo que en el ser vivo y por naturaleza el alma manda y el cuerpo es mandado, es decir, hay un dominio señorial y político: "pues el alma ejerce sobre el cuerpo un dominio señorial, y la inteligencia sobre el apetito un dominio político y regio" ${ }^{13}$; también en la ciudad, en la real y en la ideal, el hombre por naturaleza, para mantener ese equilibrio, ha de gobernar con justicia decidiendo en momentos críticos lo correcto (hablábamos antes de

la Grecia clásica, Istmo, 2003; o el de N. Loraux: La ciudad dividida, Katz Editores, Madrid, 2008.

${ }^{8}$ Política, $1253 a$

${ }^{9}$ Debo esta referencia y la pista que vincula ciudad con organismo vivo a la Profesora Susana Gómez, del Dpto. de Lógica y Filosofía de la Ciencia de la UCM.

${ }^{10}$ (2007) KOSELLECK, Reinhart: "Apéndice. Crisis" en Crítica y crisis. Un estudio sobre la patogénesis del mundo burgués, op. cit., p. 244.

${ }^{11}$ Ibid, p. 242.

12 Aristóteles definirá la ciudad como una unidad conformada por una cierta multitud de ciudadanos $(1274 b ; 1254 a)$, concebida precisamente, podemos decir, como partes de la misma.

${ }^{13} 1254 b$ 
condenas, de legislación, de guerras) Una crisis, no en vano, pone al individuo en relación con el todo del que forma parte, vincula al ser humano con su sistema y le sitúa en la encrucijada de tener que buscar una solución ante una situación insostenible o peligrosa para su supervivencia ${ }^{14}$. De ahí, que, inmediatamente despues, en el libro II Aristóteles analice las constituciones más perfectas. Pero el cuerpo de la ciudad en Aristóteles no se agota en la forma de gobierno, y a la hora de hablar de la ciudad como tal, de cómo debiera ser la ciudad perfecta, le proporciona, como buen hijo de médicos, las indicaciones adecuadas para una larga y próspera vida en una descripción que implica no sólo un número determinado de habitantes (su peso ideal), un tamaño (la proporción ideal), una situación geografica concreta, de clima cálido no exenta de sol y playa (próxima, pero no en demasía) y de una temperatura perfecta $^{15}$, e incluso la importancia de la calidad de las aguas o el régimen de lluvias $^{16}$, sino tambien claves para un correcto funcionamiento de sus partes ligadas a su peculiar forma de entender el equilibrio, algo así como un manual de higiene política [1].

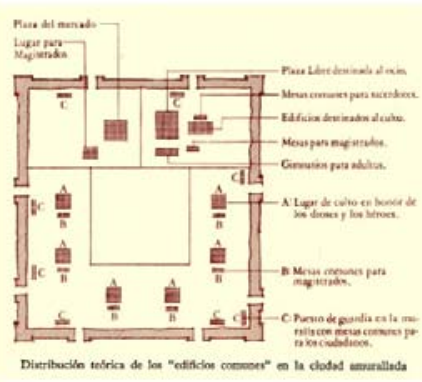

Y así Aristóteles recuerda a Hipodamo de Mileto "que inventó el trazado de las ciudades y diseñó los planos del Pireo [...] y fue el primero que, sin ser político, intentó hablar sobre el régimen mejor"17. Si la ciudad es un cuerpo natural, el urbanismo entonces sería una intervención quirúrgica [2-3] cuyo fin sería el de mejorar la vida del sujeto (o mejorar su estética, según se mire). La planificación urbana como operación curativa (el plan Cerdá, en una Barcelona insalubre y oprimida), preventiva (como el caso Hausmann y los boulevares en Paris, como hace ver W. Benjamin ${ }^{18}$ ) o estética (¿Madrid Río?).

\footnotetext{
${ }^{14}$ (2013) VILLACAÑAS, José Luis: "Crisis: ensayo de definición”, en Vínculos de historia 2, p. 136.

1326

${ }^{16} 1329 \mathrm{~b}$

${ }^{17}$ Política, 1267b

${ }^{18}$ Cfr. (2001) BENJAMIN, Walter: "Haussmann o las barricadas". En Iluminaciones II. Poesía y capitalismo, Taurus, Madrid, pp. 187-190.
} 


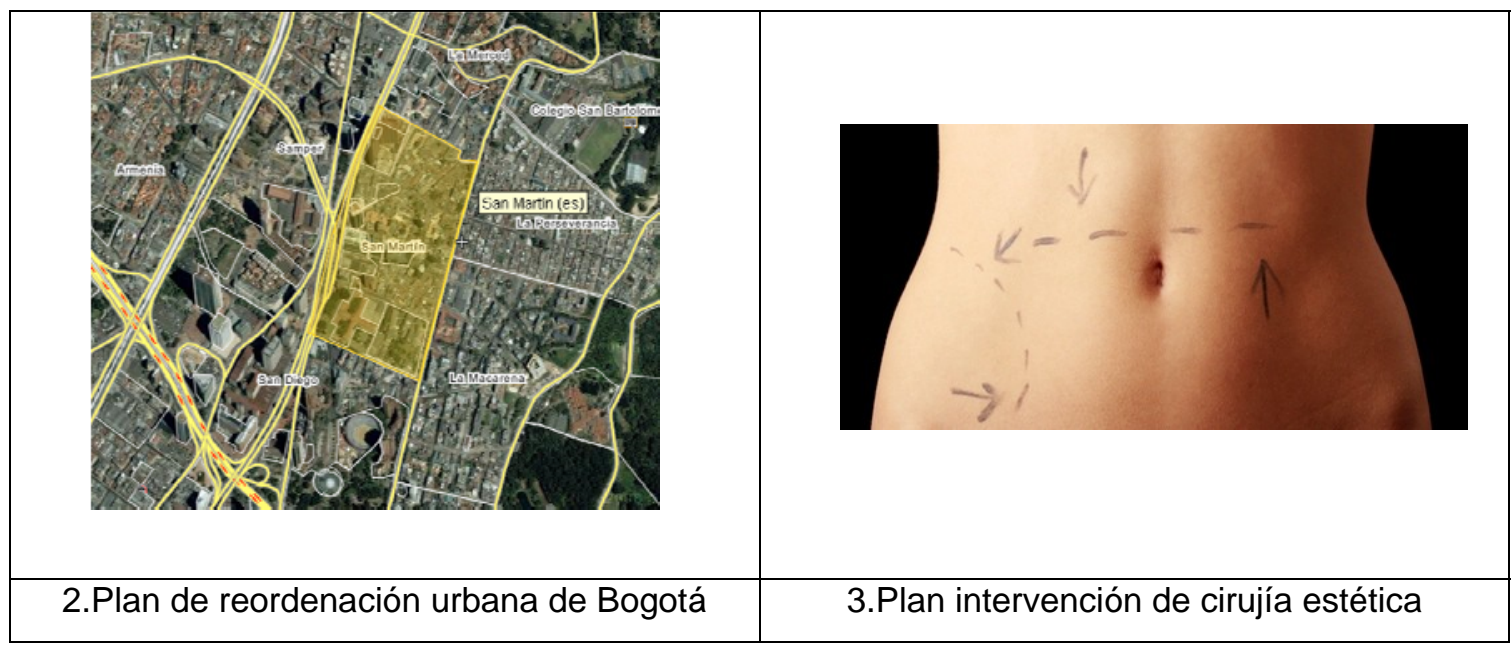

La ciudad, es por ello, un cuerpo, pero compuesto de algo en cierta medida "incorporeo" o, mejor dicho "invisible" en cuanto tal, que tiene que ver con el gobierno y el dominio político y señorial, y de algo corporeo o visible, asociado a la estructura de sus calles, su disposición, etc, ligado, si se quiere, a lo urbano mismo incluidos los moradores de ese espacio. Sin embargo, para Aristóteles, como se sabe, no existen el alma por un lado y el cuerpo por otro, sino que, aunque la distinción puede ser pensada, no se da en el hombre real o, empleado en su analogía con el ser vivo, en la ciudad. Cuando el hombre, tras una crisis, muere, se produce un cambio sustancial, lo que supone la pérdida de la forma y la adquisición de otra por parte de la sustancia "hombre": la forma que se pierde es la de "ser vivo" ("ser animado"), y la forma que se adquiere es la de "cadáver" ("ser inanimado"). El alma es la forma específica de un cuerpo natural -como el de la ciudad- que tiene vida. El cuerpo, tal y como se afirma en el De anima, queda definido como sujeto y materia ${ }^{19}$. El alma de la ciudad serán sus ciudadanos; su cuerpo, la corporalidad misma de la ciudad, incluidos habitantes de segunda, sujetos de la oikonomia de la ciudad, como esclavos y mujeres; y el fin mismo de la ciudad, como la del organismo: vivir "el bienestar es [...] el fin principal tanto de todos en común como aisladamente. Pero también el mero vivir [...] Pues quizá en el mero hecho de vivir hay una cierta parte del bien"20. Podríamos ir un poco más lejos y, aplicando los principios del epicureísmo señalar que en la ciudad, como soma, se anudarían en un mismo "recipiente" el alma, entendida como psiqué, que estaría encarnada por los ciudadanos (la mente que ha de guiar al cuerpo), y su carne, o, mejor la carnosidad de la ciudad (sarx), aquella sobre la que se interviene y que padece los síntomas de los males corporales y espirituales.

Descendiente de una familia de médicos, perteneciente a las exclusivas Asklepiadas, a Aristóteles no podía pasársele por alto la importancia del equilibrio interno en el organismo afirmada por Hipócrates, de quién llegará a afirmar que fue el más grande de los médicos de su tiempo. Si la ciudad es un cuerpo, para estar sano, necesita de un correcto funcionamiento, que pasa, para evitar el motín y la inestabilidad, hinchazones y otro tipo de dolencias, por una fuerte clase media que proporcione estabilidad al conjunto: "La ciudad debe estar construida lo más posible por elementos iguales y semejantes, y

\footnotetext{
${ }^{19}$ De anima, $412 \mathrm{a}$

${ }^{20}$ Política, $278 b$
} 
esto se da sobre todo en la clase media, de modo que una ciudad así es necesariamente la mejor gobernada, formada de los elementos que decimos es la composición natural de la ciudad"21. En este sentido, la crisis en la polis tendría que ver con un desequilibrio interno del cuerpo a través del exceso o del defecto, por ejemplo, de pobres o de clases adineradas, que o bien codician lo ajeno o, avaros, protegen lo suyo; por movimientos que tratan de ir contra natura y no acatan aquello que la psique o el gobernante dictamina. "Mandar y obedecer no son sólo cosas necesarias, sino también convenientes, y ya desde el nacimiento algunos están destinados a obedecer y otros a mandar [...] Dondequiera que uno manda y otro obedece hay una obra común. En efecto, en todo lo que consta de varios elementos y llega a ser una unidad común, [...] aparecen siempre el dominante y el dominado" ${ }^{22}$. La carne no puede ir separada de la mente. Lo sano, como lo justo, significa no transgredir la ley y atacar el orden con el fin de preservar el interés común ${ }^{23}$. El político, como el médico, ha de aplicar entonces una justicia como técnica curativa o preventiva $^{24}$. $\mathrm{Y}$, del mismo modo que, cuando habla de la técnica médica o cuando procede a estudiar las enfermedades de los animales, Aristóteles, a través del análisis de formas de gobierno y tipos de gobernantes, considerará claves en el éxito y supervivencia de la ciudad la observación y la experiencia.

Quien entendió y muy bien la estructura de la ciudad en términos médicos fue en el siglo XVI el ya mentado Francesco Patrizzi, quien, en su Ciudad feliz (1553), se ocupó del lugar propio en el que la ciudad debe establecerse recomendando, como Aristóteles, climas cálidos al igual que el cuerpo para estar sano ha de evitar situaciones de frío o calor extremo, y afirmando la necesidad de la existencia de movimiento de aire para favorecer la sana respiración de sus habitantes. No en vano estudió, además de matemática y filosofía, medicina. Pero ya antes el arquitecto romano Vitrubio hablaba de la necesidad de que la ciudad fuera entendida proporcionalmente con el cuerpo humano. En todo caso, esta concepción de la ciudad como cuerpo no es, en nuestro tiempo, nada nuevo: la mención al corazón de la ciudad o de centro neurálgico, las arterias referidas a la circulación, las referencias al pulmón de la ciudad inciden en esta idea, pero fue, sin embargo, Aristóteles quien fue más allá de la mera metáfora: si la ciudad es ella misma un cuerpo, lo natural característico del hombre, entonces, afirmamos nosotros, ha de manifestar en su propia carne los síntomas de su crisis. El cuerpo de la polis constituye el espacio de manifestación de la crisis.

Un buen estudioso del idealismo alemán diría que más importante que el alma es el espíritu y más importante que el cuerpo es el proceso mismo de su evolución y devenir. El espíritu es la vida de un pueblo y, como tal, lo que se va revelando a través de una manifestación o exteriorización de lo que es interior. Un dar señal de sí que significa un estar vivo. Y aunque Hegel, que afirmaba la realización del espíritu en el tiempo, acaba matando en su inmovilidad la vida del todo (hablará en el prefacio de la Fenomenología del "cadáver que se deja

\footnotetext{
${ }^{21} 1295 b$.

22 Política, 1254a

23 Ética a Nicómaco, 1129b

${ }^{24}$ Ética a Nicómaco, 1131a y ss.
} 
tras de sí" en el proceso) ${ }^{25}$. Schelling, en cambio, hablará de una realización que produce cambios continuos, "envejecimientos" en el tiempo, y que por ello se articula en torno a las edades del tiempo, edades del mundo, entendidas como edades del Sujeto de la Historia [4].

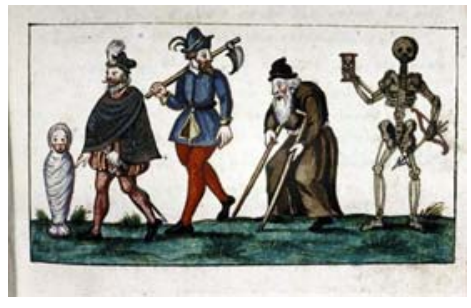

\section{Edades del Hombre. Tratado Alquímico XVII}

De ahí que, aunque el espíritu sea el que aliente el proceso histórico y natural del devenir, cada época está caracterizada por una forma o figura distinta de ese mismo espíritu. Y lo que enferma es, justamente, el espíritu mismo. Piénsese en el concepto de mal en la filosofía de Schelling: la historia misma, cuerpo del espirítu, muestra pruebas inequívocas, "síntomas" de su enfermedad (la crisis en este contexto acontecería cuando aquello que, recuerda Freud citando a Schelling "debiendo haber permanecido secreto, oculto... no obstante, se ha manifestado"26). La ciudad, según lo dicho, también envejecería, pero mostraría en su cuerpo, como bien vio Benjamin, la simultaneidad de los tiempos a través de un "paisaje de la memoria"27.

\section{SINTOMATOLOGÍA DE LA CRISIS EN EL CUERPO DE LA CIUDAD}

Vivimos en tiempos de crisis o tal vez la sensación de crisis, que ya no es crisis entendida en sentido médico, sino una forma paulatina de empobrecimiento, es decir, ya no punto o momento "clave" de vida o muerte, sino línea agónica, ya casi tediosa -de ahí la evolución semántica y la equivocidad del concepto tratada en otros lugares ${ }^{28}$-, es nuestro espíritu de época. Por eso no estamos

${ }^{25}$ GW (=G.W.F. Hegel Gesammelte Werke) 9, 11; trad. de Roces, Wenceslao en (ed. 1999) Hegel, G.W.F: La fenomenología del espíritu, México, Fondo de Cultura Económica, Madrid, p. 8.

26 (2006) FREUD, Sigmund: "Lo siniestro". En Obras completas, tomo 7, Madrid, Biblioteca Nueva, 2006, p. 2487. Para profundizar en esta lectura y la relación de Schelling con lo siniestro freudiano Cfr. GODDARD, Jean-Christoph: "Freud et Schelling. Unheimlichkeit et refoulement". En (2012) FERRER, Diogo -PEDRO, Teresa (Eds): Schellings Philosophie der Freiheit. Studien zu den Philosophischen Untersuchung über das Wesen der menschlichen Freiheit, Ergon Verlag, Würburg, pp. 277-285

${ }^{27}$ Me permito remitir a mi trabajo "Espacio de olvido, construcción del recuerdo. O sobre las consecuencias de derribar un muro" que saldrá próximamente en el volumen colectivo: VILLACAÑAS, José Luis - LAPAYESE, Concha - CARRASCO CONDE, Ana: Paisajes filosóficos: memoria y ciudad, La Oficina de Arte y Ediciones, Madrid.

${ }^{28}$ Sobre los relatos y derivas del concepto crisis, contamos muy recientemente con el volumen colectivo de CADAHIA, Luciana-VELASCO, Gonzalo: Normalidad de la crisis / Crisis de la normalidad, Madrid, Katz, 2012. 
en "estado crítico", sino que nuestro estado o nuestra era, por parafrasear el título de uno de los libros de Félix Duque, es la era de la crisis (recuérdese la cercanía conceptual de crisis y crítica) ${ }^{29}$. Y por eso nuestra situación se extiende en el tiempo en una forma de lento presente, por decirlo con Gumbrecht $^{30}$, en el que parece no haber futuro ${ }^{31}$. La ciudad como cuerpo espacial de este espíritu manifiesta una sintomatología bien clara. El cuerpo orgánico presenta formas de manifestación de la enfermedad, como las presentan las ciudades de la crisis. Como dice Sabina, pongamos que hablo de Madrid, aunque también, recordando a George Moustaki, podríamos hablar del caso Atenas. Es el hermanamiento del sur del Europa del que gráficamente se ha hecho cargo de forma inquietante Dimitris Hantzopoulos [5 y 6].

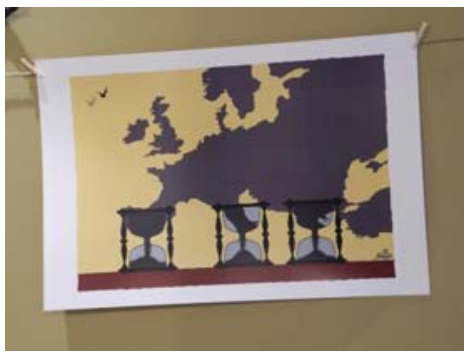

5. Hantzopoulos (2011)

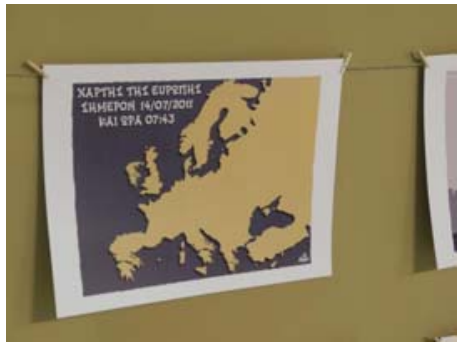

6. Hantzopoulos (2011)

Entre los síntomas físicos de una enfermedad encontramos el dolor intangible, visible sólo a través de sus efectos; así como otros síntomas como la inflamación, los vómitos, la supuración, la incapacidad de emplear normalmente algunos órganos o partes del cuerpo. Tanto Atenas como Madrid han presentado estos síntomas a través de su lenguaje urbano. Es hora de la clínica, del reconocimiento de los síntomas. En Crítica y clínica Deleuze sostiene que ante la enfermedad es preciso, incluso en opinión de Freud, confeccionar un mapa, un medio que "se compone de cualidades, de sustancias, de fuerzas y acontecimientos: por ejemplo la calle, y sus materiales como los adoquines, sus ruidos como las voces de los vendedores, sus animales como los caballos atados a los carros, sus dramas [...] El trayecto no sólo se confunde con la subjetividad de quienes recorren el medio, sino con la subjetividad del medio en sí en tanto que éste se refleja en quienes lo recorren. El mapa expresa la identidad del itinerario y de lo recorrido"32. En la calle, en los adoquines, en las voces y ruidos, en los muros, en las plazas y en los modos y maneras de las aglomeraciones se han ido mostrando diferentes síntomas. En época de crisis el cuerpo de la polis sufre, como dijera Hipócrates, un desequilibro interno, que hace que el régimen ya no sea estable y su pervivencia se ponga en peligro de muerte. De nuevo, la Política de

\footnotetext{
${ }^{29}$ El título de este libro es La era de la crítica. Historia de la filosofía moderna, Akal, Madrid, 1998.

${ }^{30}$ (2010) GUMBRECHT, Hans Ulrich: Lento presente. Sintomatología de un nuevo tiempo histórico, Escolar y Mayo, Madrid.

${ }^{31}$ Cfr. (2013) Rocío Orsi y Andrés González: "La construcción mitológica de la crisis". Disponible: http://www.aecpa.es/uploads/files/modules/congress/11/papers/973.pdf (Consultado el 9 de diciembre de 2013)

32 (2009) DELEUZE, Gilles: "Lo que dicen los niños". En Crítica y clínica, Barcelona, Anagrama, pp. 89-90.
} 
Aristóteles: "Las democracias son más firmes y más duraderas que las oligarquías gracias a sus clases medias [...], pero cuando, en ausencia de estas clases, los pobres se extienden demasiado en número, surge el fracaso y pronto desaparecen"33. Una de las grandes consecuencias de nuestro espíritu de época, ligado a la crisis, está siendo, precisamente, la eliminación progresiva de la clase media. De hecho, se estima que en 2012 el 21,1\% de la poblacion española estaba ya en riesgo de pobreza $^{34}$ (y un 5,8\% en una situación de privación material severa), frente al 23\% de los griegos. Sin duda, de seguir esta analogía de la polis con un sistema orgánico, el cuerpo padecería los efectos de un grave desequilibrio interno.

\section{a) El dolor}

El primero de estos síntomas ha sido el dolor. Dolor ante la falta de trabajo, dolor ante el desahucio, dolor ante el miedo, dolor ante la falta de expectativas, dolor ante los remedios aplicados por la psique del gobernante. Pero del dolor que en verdad se siente, recordando los versos de Pessoa, sólo puede dar cuenta quien lo padece no manifestando el dolor mismo, por la imposibilidad de expresar lo más propio, sino su imagen o expresión. Ante el dolor que se siente en propia carne sólo caben dos salidas: o el silencio o el grito. Decidirse por el grito se refleja en la carne (sarx) de la ciudad a través de graffitis [7], de mensajes de queja escritos en las paredes $[8,9]$ e incluso expresiones de desesperanza [10].
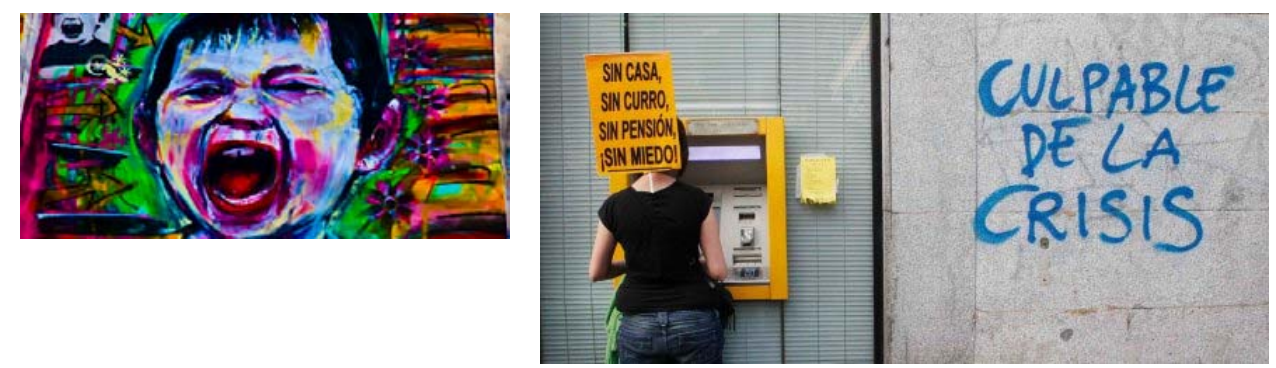

7. Graffiti grito (Madrid)

8. Pintada "Culpable de la crisis" (Madrid)
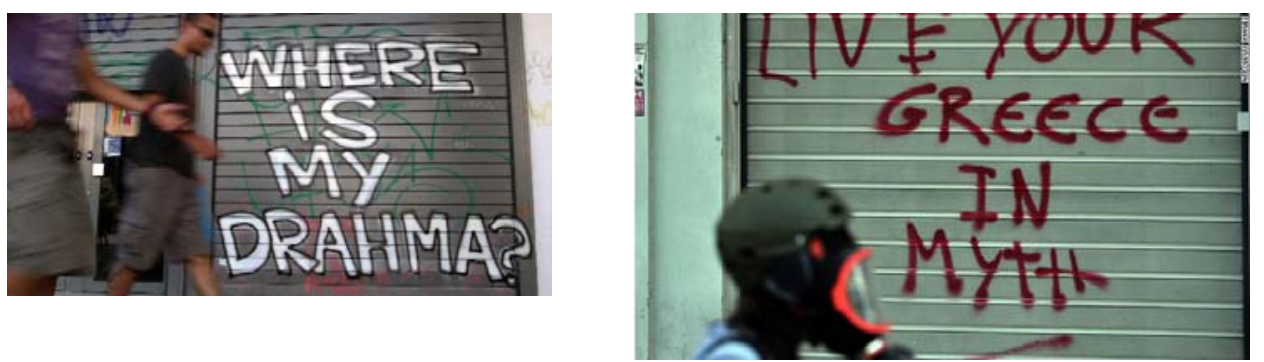

9. Pintada "Where ist my drahma?" 10. Pintada "Live your greece in myth (Atenas) (Atenas)

\footnotetext{
${ }^{33}$ Política, 1296a

${ }^{34}$ Dato extraído del texto ya citado de Orsi y González. "La construcción mitológica de la crisis" (2013). Es interesante en este punto de nuevo este artículo para analizar el mito acerca de la conspiración de los más ricos.
} 
La piel de la ciudad se cubre de tatuajes, como forma de exteriorización en la carne de la mortificación interna que padecen sus ciudadanos. Cuerpo pues, que narra su historia. Cuerpo que testimonia la evolución y devenir del sujeto, de su historia con elementos de gran significación. El cuerpo tatuado "habla de las memorias y proyectos del sujeto: de sus dichas, desdichas, ansias, temores, ideales, lealtades, ideologías, convicciones y luchas"35. Si la identidad del sujeto utiliza su cuerpo como medio de subjetivación, la ciudad como tal forma parte a su vez de este proceso, de la afirmación y de la construcción de la identidad de sus moradores como pueblo. De hecho, si el dolor individúa y se dirige hacia lo más interno y personal de uno mismo, hacia lo más propio, las exteriorizaciones del malestar y del dolor de la ciudadanía o de un grupo suelen estar ligadas a la afirmación de aquello que los une, que no es el dolor, sino una identidad común. Recuérdese el mar azul y blanco de banderas ondeantes en la plaza Sintagma de Atenas [11]. El peligro es, en este caso, la exaltación nacionalista (justificada o no), que hace que en momentos de crisis los hombres busquen la protección de aquello que les permita eliminar su dolor (como en el caso de la estrecha victoria de Hitler tras las elecciones de 1933, en un clima, también de crisis económica y escasez).

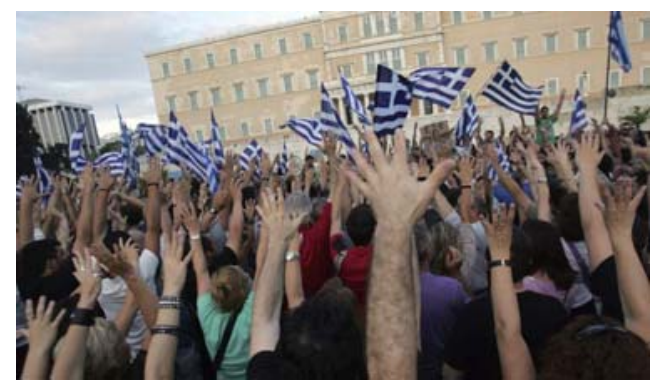

11. Plaza Sintagma (Atenas)

b) El vómito

Un síntoma claro de la enfermedad en el cuerpo (soma) que aúna alma (psique) y carne (sarx) es el vómito. Que, en medicina, normalmente es causado por la incapacidad del organismo de asimilar lo ingerido, bien por el rechazo del propio cuerpo ante algo que le hace daño o bien ante la angustia y el miedo. El cuerpo de la crisis no puede sin embargo expulsar fuera de sí lo que le causa daño, pero sí puede manifestar la nausea: deuda, cambio, ricos, pobres, crisis [12].

\footnotetext{
${ }^{35}$ (2011) SASTRE CIFUENTES, A.: "Cuerpos que narran: la práctica del tatuaje y el proceso de
} subjetivación“. Revista Diversitas. Perspectivas en Psicologia, vo. 7, №1, p. 182. 


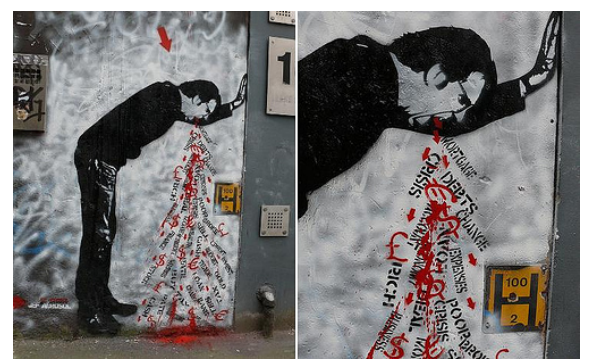

12. Graffiti (Londres)

c) Inflamación

Otro síntoma que experimenta el cuerpo de la ciudad ante la enfermedad es la inflamación o hinchazón, entendida, patológicamente como una "alteración en una parte cualquiera del organismo, caracterizada por trastornos de la circulación de la sangre y, frecuentemente, por aumento de calor, enrojecimiento, hinchazón". La inflamación de la ciudad, el colapso de sus calles, la ocupación de sus plazas, se produce a través no de modificaciones o cambios en la carne, sino en la aglomeración intensa de elementos que forman parte del cuerpo de la ciudad [13 y 14]: lo que da vida a la misma, su sangre, sus ciudadanos (no es preciso señalar la relación que desde la Antigüedad han tenido la vida y la sangre, relación, por cierto, que ha pasado a la mitología popular a través de la figura del vampiro). Las plazas, las grandes arterias de la ciudad se convierten en el lugar manifestación de inflamación, que llega incluso a un aumento del calor y de los ánimos [15]. De ahí, por cierto, la importancia del diseño de la ciudad que no se reduce a la funcionalidad de las estructuras urbanísticas, sino que interviene directamente en el espacio en el que vivimos y que condiciona nuestra forma de habitar y de relacionarnos con los otros. Como cirujía preventiva, Haussmann, por ejemplo, en su planificación urbana de París, lo que trató es de eliminar la posibilidad de manifestación del síntoma, esto es, evitar los amotinamientos y luchar contra las barricadas revolucionarias ${ }^{36}$.

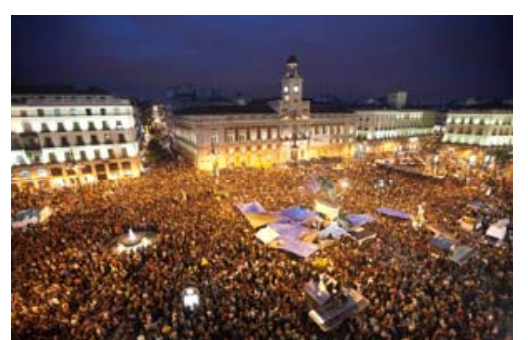

13. Puerta del Sol (Madrid)

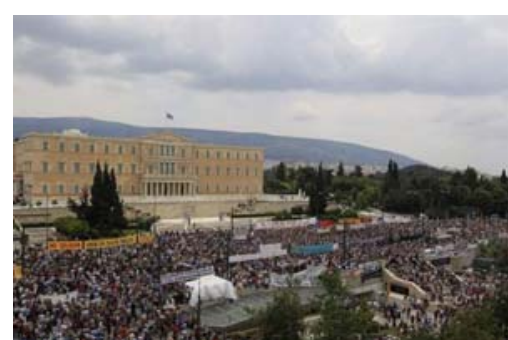

14. Plaza Sintagma (Atenas)

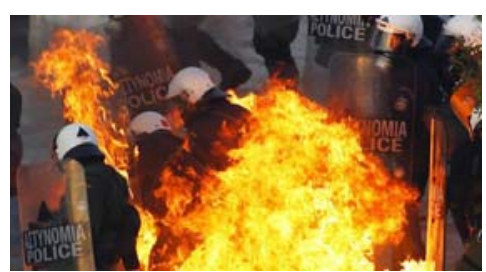

15. Altercados Atenas

\footnotetext{
${ }^{36}$ BENJAMIN, Walter: "Haussmann o las barricadas", op. cit., pp. 187-190.
} 
d) Supuraciones y malos olores

[16 y 17] Tanto en Atenas como en Grecia los recortes, la amenaza del paro, la suspensión de pagos han tenido otro efecto: la supuración a través de los desechos y el hedor de las calles, provocados por las huelgas de basura. Ambos efectos suelen ir ligados a la idea de la falta de vida, bien por putrefacción de la carne, bien, como es el caso, por funcionamiento anómalo de los órganos encargados de la eliminación de tales elementos.

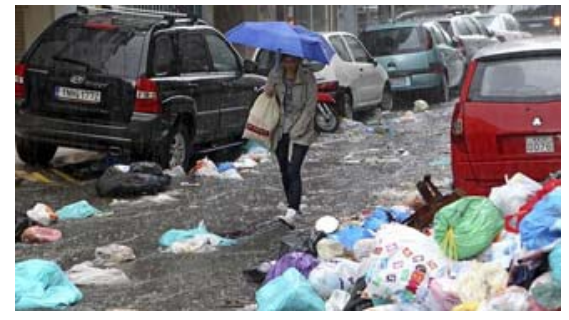

16. Huelga basura Atenas 2012

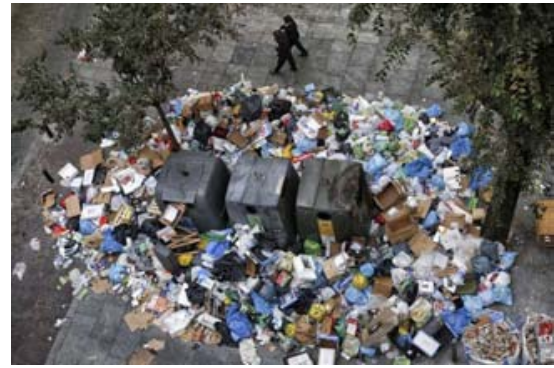

17. Huelga basura Madrid 2013

e) Inmovilidad o incapacidad de órganos y partes del organismo

Pero el funcionamiento anómalo, o la incapacidad de algunos órganos o partes del mismo de ofrecer sus servicios es, también, parte de los síntomas. La ciudad queda inmovilizada y los intercambios entre sus habitantes reducidos al mínimo. Es el caso, por ejemplo, de la quiebra de empresas y del cierre de establecimientos comerciales. [18] Si la sangre son los ciudadanos, aquello que la oxigena y la bombea, es, precisamente lo primero que sufre en una crisis: el motor (el dinero en el caso económico, lo emocional en el caso personal, la ideas en una crisis creativa). $Y$ este mal funcionamiento lleva a la inmovilidad [19].

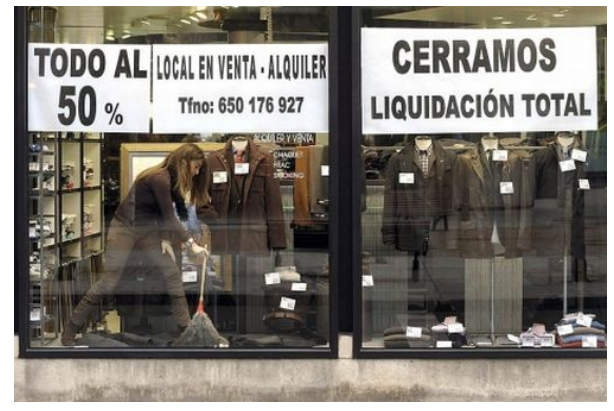

18. Cierre de locales (Madrid)

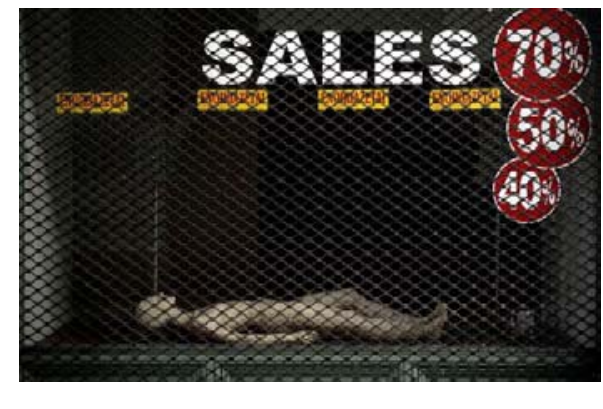

19. Cierre de locales (Atenas) 


\section{LA ENFERMEDAD Y EL HORIZONTE DE EXPECTATIVAS}

Después de haber enumerado estos síntomas, volvamos de nuevo Koselleck. El concepto de crisis sale del restringido ámbito médico, jurídico e incluso teológico en el Sattelzeit, final del XVIII y comienzo del XIX, para comenzar a emplearse en la política, en la economía y en el ámbito personal, hasta el punto de que el concepto "crisis" como tal constituye la marca -Signatur- de la experiencia temporal de la modernidad, que ya no implica un momento clave, de vida o de muerte, y que, como tal, al ser constitutivo de una época, no se opone a nada. Si antes la crisis era la excepción de la normalidad, ahora encontramos, ligado al espíritu de una época, una normalidad en la crisis. Desde la filosofía de la historia la labor no es fácil porque ha de incluir en su discurso no ya -0 no sólo- un punto de ruptura ${ }^{37}$, sino una figura, otra más, en la historia, que ni es astucia de la razón ni nos lleva al progreso, la forma de un empobrecimiento que, si se remonta, no es síntoma de recuperación, sino síntoma, simplemente, de un nuevo tiempo. En la vida, como en la historia, los periodos de crisis no son menos vida ni son menos historia, no hay menos yo en la enfermedad, como no hay menos identidad en los pueblos que la padecen, son otra forma de experiencia y de conocimiento de uno mismo, que, eso sí, si te mata o te hace más fuerte se debe a la decisión vital fruto, ahora sí, de un momento de enjuciamiento y crítica. La crisis no se curan. Las crisis se remontan y, cuando así se hace, se posibilita la recuperación ante una situación que no tenía salida: tal vez un nuevo comienzo, tal vez una forma de purga y catarsis que nos permite seguir viviendo.

Lo que caracteriza a nuestro tiempo de normalidad en la crisis es sin embargo una determinada concepción del tiempo, que hace de su transcurso una eternidad. Un lento presente. De nuevo Gumbrecht. O un presente extendido, como afirma Helga Nowotny, que hace que se diluya el tiempo por venir y las expectativas, un tiempo presente que se extiende hasta ocupar el resto del tiempo: "Esa ausencia de futuro que prolonga inconsistentemente el punto crítico es lo que [...] nos llevará a sospechar que la crisis que estamos viviendo se parece más bien a un anormalmente indefinido estado de excepción permanente que a alguna forma de saludable kátharsis"38. La ausencia de futuro es lo que teme el enfermo, el cuerpo presente, que absolutamente idéntico consigo mismo, significa la petrificación del cuerpo, del todo y con ellos la reducción al polvo de una mano que, resquebrajada, pierde su funcionalidad. La inmovilidad. Éste parece ser el elemento que define nuestro tiempo histórico, el del tiempo que no pasa o que cortocircuitado ya no aspira a futuro alguno y el único pasado que le queda es el del recuerdo deformado de los buenos tiempos, que quizá nunca fueron tan buenos.

El tiempo de la crisis, nuestra normalidad, queda definido como el momento del permanente desencuentro e incomodidad, lo que nos obliga a salir de nosotros mismos para superar una situación porque algo que no está dónde debería, porque lo inasimilable, lo anómalo, sale a la luz. Es nuestra edad del hierro hesiódica, frente a la dulce época de los hombre de oro (a la que nunca, por

\footnotetext{
${ }^{37}$ Sobre el sentido de la crisis como ruptura y su relación con las categorías de la filosofía de la historia, remito al lector a mi "Blow up. Evento, acontecimiento, crisis". En CADAHIA,LuciaaVELASCO,Gonzalo: Normalidad de la crisis / Crisis de la normalidad, op. cit., pp.123-137.

${ }^{38} \mathrm{http}: / /$ elblogdelaeconomia.blogspot.com.es/2013/09/el-estado-actual-del-enfermo-que.html (Consultado el 9 de diciembre de 2013)
} 
cierto, realmente perteneció a nuestra estirpe mortal). O, mejor dicho, nuestro momento extendido en el tiempo en el que aflora y hiede lo que permanecía soterrado, escondido en la sombra, y que es preciso remontar para seguir. Quizá por ello exista una relación entre una crisis y los momentos de terror: porque aparece lo desconocido y la angustia del vacío bajo los pies. Pero es nuestra decisión saber, si no cómo combatir la enfermedad, sí como enfrentarnos al miedo. No fue Aristóteles, ni Tucídides, ni tampoco Hipócrates, sino mi buen Schelling, que mucho sabía de crisis especulativas, políticas y personales, y que afirmó la imposibilidad de reducir la existencia al mero concepto, quien afirmó, frente a la paloma kantiana, que "la fuerza del águila en vuelo no viene probada por el hecho de que no sienta ninguna tendencia hacia abajo, sino porque la supera y se sirve de ella como medio para elevarse" ${ }^{\text {"3 }}$.

${ }^{39} \mathrm{SW} \mathrm{I/10,} 177$. 